\title{
Recovery of vestibular ocular reflex function and balance control after a unilateral peripheral vestibular deficit
}

\author{
J. H. J. Allum* \\ Division of Audiology and Neurootology, Department of ORL, University Hospital of Basel, Basel, Switzerland
}

Edited by:

Pierre-Paul Vidal, Universite Rene

Descartes/Centre National de la

Recherche Scientifique, France

\section{Reviewed by:}

Aasef G. Shaikh, Case Western Reserve University, USA

Richard Fitzpatrick, Neuroscience

Research Australia, Australia

${ }^{*}$ Correspondence:

J. H. J. Allum, Division of Audiology and Neurootology, Universitätsspital Basel, CH-4031 Basel, Switzerland. e-mail: jallum@uhbs.ch
This review describes the effect of unilateral peripheral vestibular deficit (UPVD) on balance control for stance and gait tests. Because a UPVD is normally defined based on vestibular ocular reflex (VOR) tests, we compared recovery observed in balance control with patterns of recovery in VOR function. Two general types of UPVD are considered; acute vestibular neuritis (AVN) and vestibular neurectomy. The latter was subdivided into vestibular loss after cerebellar pontine angle tumor surgery during which a vestibular neurectomy was performed, and vestibular loss following neurectomy to eliminate disabling Ménière's disease. To measure balance control, body-worn gyroscopes, mounted near the body's center of mass (CoM), were used. Measurement variables were the pitch (anterior-posterior) and roll (lateral) sway angles and angular velocities of the lower trunk/pelvis. Both patient groups showed balance deficits during stance tasks on foam, especially with eyes closed when stable balance control is normally highly dependent on vestibular inputs. Deficits during gait were also present and were more profound for complex gait tasks such as tandem gait than simple gait tasks. Major differences emerged between the groups concerning the severity of the deficit and its recovery. Generally, the effects of acute neuritis on balance control were more severe but recovered rapidly. Deficits due to vestibular neurectomy were less severe, but longer lasting. These results mostly paralleled recovery of deficits in VOR function. However, questions need to be raised about the effect on balance control of the two modes of neural plasticity occurring in the vestibular system following vestibular loss due to neuritis: one mode being the limited central compensation for the loss, and the second mode being some restoration of peripheral vestibular function. Future work will need to correlate deficits in balance control during stance and gait more exactly with VOR deficits and carefully consider the differences between insufficient central compensation compared to inadequate peripheral restoration of function.

Keywords: balance control, stance, gait, unilateral peripheral vestibular deficit, vestibulo-spinal reflexes, vestibuloocular reflexes, recovery mechanisms following vestibular loss

\section{HOW TO DEFINE A UNILATERAL PERIPHERAL VESTIBULAR DEFICIT?}

It is necessary to consider this question before embarking on a description of the types of unilateral peripheral vestibular deficit (UPVDs) and the ensuing effects on balance control. Vestibular ocular reflex (VOR) measurements are typically used to provide information on the extent of this deficit. Thus the VOR techniques used influence the definition of the UPVD. Essentially we are asking the question: what is or what should be the "gold standard" for defining a UPVD? Both the deficit type (whether a vestibular neurectomy is involved or vestibular neuritis) and deficit recovery (or lack thereof) alter the VOR in a different way when measured in the yaw and pitch planes (Allum et al., 1988a,b; Aw et al., 1999). Thus it is clear that the VOR deficit must be accurately defined. A problem arises, however, because these VOR changes even in one plane appear to yield different results when measured with low accelerations (maximally $80^{\circ} / \mathrm{s}^{2}, 240 \%$ ) applied using whole body rotations (Allum et al., 1988a; Allum and Ledin, 1999) compared to measurements with high impulsive accelerations (ca. $2000^{\circ} / \mathrm{s}^{2}$, $200^{\circ}$ s) applied with rapid head turns (Cremer et al., 1998; MacDougall et al., 2009; Manzari et al., 2011). Despite these differences the VOR responses measured with either of these two techniques could be used to provide information on the extent of an UPVD and its possible recovery (Allum et al., 1988a,b; Allum and Ledin, 1999; Palla and Straumann, 2004) provided stimulus velocities mimicked head velocities during balance tests. The fundamental question thus is whether either of these two VOR test techniques adequately represent VOR responses for head velocities occurring during stance and gait balance tasks. Tests with low head acceleration and velocities around $40^{\circ} / \mathrm{s}^{2}$ and $120 \%$, respectively, mimic those of gait tasks such as rising from a chair for which head pitch velocities rarely exceed $50 \%$ over the 1 -s get-up phase. However, the head velocities measured during walking while looking from side to side are more rapid than those elicited by whole body rotation, but slower than those imposed by head impulse test techniques (see Figure 1). Neither of these techniques uses tests with stimuli representing the slow head velocities of $210 \%$ observed during stance tests (Honegger et al., 2012). 


\section{Walking while rotating the head left to right}

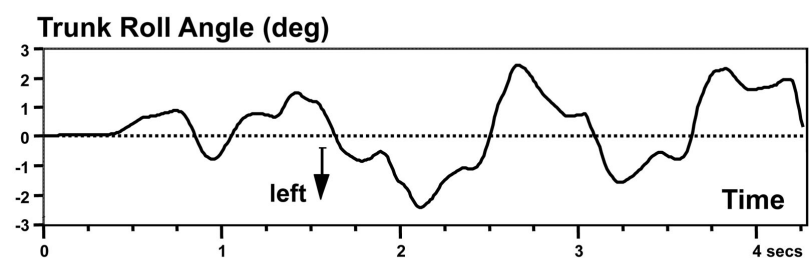

Head Yaw Angular Velocity (deg/s)

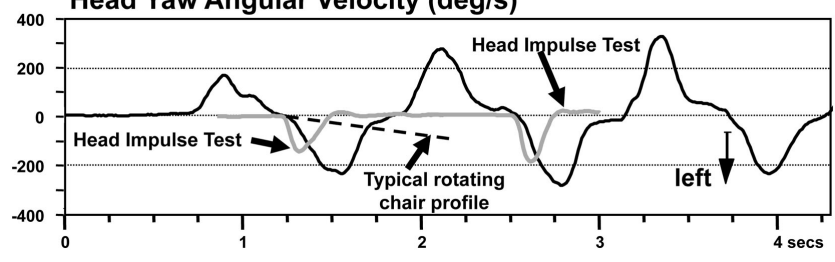

FIGURE 1 | Comparison of head velocities during a gait test with those from a head impulse test (HIT) and a typical rotating chair velocity profile. The upper trace shows the lower trunk roll movements during walking while rotating the head left and right in pace with gait. The lower trace shows the head velocity in comparison to two HIT records and one rotating chair record. Although the amplitude of head velocity is comparable in the HIT test, the accelerations are clearly faster for the HITs, slower for the rotating chair.

Thus there are limitations and, not surprisingly, differences of opinions (see Curthoys, 2000) concerning how accurately VOR techniques measure the extent of a UPVD. Clearly, VOR measurements can not provide all the information needed to characterize the vestibular component of the balance disability experienced by UPVD patients during stance and gait, rather a conglomerate of VOR tests helps provide an estimate of the peripheral vestibular deficit. The caloric test only provides information on the absence or restoration of peripheral function. For example, in cases of AVN when restoration is complete (Manzari et al., 2011), partial (Allum and Ledin, 1999; Allum and Adkin, 2003), or absent (Allum et al., 1988a). It is our opinion (see Figure 1), that neither low acceleration $\left(80 \% \mathrm{~s}^{2}\right)$, medium velocity $(240 \% \mathrm{~s})$, tests of the VOR with whole body rotations, nor tests with high acceleration, medium velocity, head impulses (Halmagyi et al., 2010) provide an accurate estimate of vestibular function for head movements occurring during natural movements of gait. These tests provide only rough bounds for this estimate.

Head impulse tests are extremely useful diagnostically ( $\mathrm{Hal}-$ magyi and Curthoys, 1988) and provide important information on the neurophysiological status of the VOR following UPVD. But, in contrast to rotating chair responses (Allum et al., 1988a,b; Allum and Ledin, 1999) there is little population information available on the time course of VOR recovery following the most common form of UPVD, that due to AVN. The population information that is available (Palla and Straumann, 2004) suggests that changes in the symmetry of VOR responses over time recorded with the head impulse tests (HIT) are similar to those recorded with low acceleration rotating chair systems (Allum and Ledin, 1999). There is, however, a problem with using HIT VOR results to track recovery from an $\mathrm{AVN}$ in form of changes in response asymmetry.
Due to interocular differences using HIT, it is necessary to measure both eyes in order to track changes in asymmetries correctly (Weber et al., 2008). Thus the failure to note a return to symmetry following AVN in HIT VOR results for a single eye (Palla and Straumann, 2004) could be due to the aforementioned interocular asymmetries.

There is, however, another reason for caution when using VOR results as the "gold standard" for estimating the vestibular spinal status after onset of a UPVD. Balance control is a result of vestibular spinal responses interacting with those from proprioceptive systems and a product of vestibular neural pathways quite separate from those of the VOR. Therefore it would not be surprising if measures of balance control relating to the size and time course of recovery from the UPVD differ from those of the VOR. However, even if measured VOR responses using HIT or rotating chair techniques do provide an estimate of vestibular function for head movements during gait as shown in Figure 1, there is still the problem of provided estimates for head movement of stance. Head movements during stance are much smaller than during gait and closer in amplitude to vestibular thresholds (Honegger et al., 2012). Thus it can be expected that a UPVD might have a more drastic effect on balance control during stance than gait simply because, during stance, vestibular sensory thresholds will be changed due to differences in resting discharges of both vestibular nuclei causing a spontaneous nystagmus of ca. $10 \%$ s (Allum and Ledin, 1999). This level of nystagmus is greater than roll head velocities of stance in healthy controls and equal to head velocities in pitch (Honegger et al., 2012).

In summary when describing the effect of UPVD on balance control in relation to VOR responses, the essential question unresolved is the VOR "gold standard" to be used to describe the level of the UPVD itself. Our current thinking for stance tests is that the level of spontaneous nystagmus is the best VOR correlate to the stance instability of a UPVD patient (Allum and Adkin, 2003) and VOR responses for low $\left(<100 \% \mathrm{~s}^{2}\right)$ accelerations the best (if inadequate, see above) correlate for balance control during gait.

\section{DIFFERENT TYPES OF UPVD}

Here we shall consider two types of UPVD: (1) AVN; (2) surgical transection of the vestibular nerve due to either the removal of a cerebellar pontine angle tumor (CPAT) or as a measure to ease debilitating Ménière's disease. Apart from differences in preoperative vestibular function, the effects of nerve transection may be considered similar for the second type of UPVD.

\section{ACUTE VESTIBULAR NEURITIS}

The clinical picture of AVN which is often attributed to a viral infection is typically one of nausea, spontaneous nystagmus beating to the healthy side and a falling tendency to the side of the deficit (Halmagyi et al., 2010). A number of weeks after the acute onset, balance problems are less profound, presumably because the mechanisms underlying peripheral recovery and central compensation for the deficit have taken place.

One of the signs of central compensation is the reduction of spontaneous nystagmus which usually takes 3 weeks to subside (Strupp et al., 1998) and which like longer processes underlying recovery in symmetry in VOR responses (Allum and Ledin, 1999) 
is associated with central bilateral adjustments of the resting discharges of vestibular nuclei (Ried et al., 1984; Vibert et al., 1999a,b). Tests of VOR function yield similar results when there has been no or the usual $30 \%$ peripheral recovery as seen in caloric tests (Allum and Ledin, 1999; Allum and Adkin, 2003). The response for low acceleration, whole body, rotations to the deficit side is decreased to $50 \%$ of normal and to the healthy side $75 \%$, when tested 35 days after the acute onset of AVN (Allum et al., 1988a; Allum and Ledin, 1999; Allum and Adkin, 2003). When tested after 3 months, the majority of patients have symmetrical responses which have been achieved by a reduction of the response for rotations to the healthy side and an increase of the response for rotations to the deficit side. This pattern is similar but less pronounced for the pitch plane (Allum et al., 1988a). As has recently been shown for head impulse testing (MacDougall et al., 2009) there are patients who do not recover symmetry in VOR responses at all (Allum and Ledin, 1999) as well as patients who recover both peripheral and VOR function completely (Herzog et al., 1997; Manzari et al., 2011). An important point to note with AVN patients is that VOR responses for rotations to the healthy side decrease in amplitude over time which can only be due to a central compensation process acting to improve response asymmetry. In contrast, VOR responses to the deficit side increase with time. The latter improvement may result from either central compensation or be due to the, on average $30 \%$, peripheral recovery observed in caloric responses (Allum and Adkin, 2003). Clearly the recovery processes will be different from those of neurectomy of the vestibular nerve for which no peripheral recovery can occur by definition. The clear statements in the literature on this point (Allum and Ledin, 1999) are often glossed over or ignored by those studying only neurectomy patients (see for example Curthoys, 2000). The crucial questions which we shall attempt to answer here are firstly whether differences in recovery rates of balance control can be observed in stance and gait tests corresponding to the changes in VOR function of AVN patients. Secondly whether these differing rates of balance recovery will also be observed for neurectomy patients.

\section{VESTIBULAR LOSS FOLLOWING NEURECTOMY}

A CPAT such as a vestibular schwannoma generally grows slowly and these patients do not experience the acute unilateral vestibular loss syndrome of AVN patients. Instead most CPAT patients appear to constantly compensate for the effects of the tumor so that VOR gains for low whole body accelerations tend to be symmetrical, if on the lower borderline of normal, prior to surgery (Allum et al., 1988b; Beule and Allum, 2006). Depending on whether the tumor was pressing on the vestibular nerve, or a section of the vestibular nerve had to be removed with the tumor, VOR gains improve post-operatively in some patients (Allum et al., 1988b) or stay permanently impaired (Beule and Allum, 2006). Tests of VOR function up to 3 years post-surgery in those with a neurectomy show that gains for rotations to the deficit side are reduced to $50 \%$ of normal whereas those to the healthy side are reduced to $80 \%$ of normal (Beule and Allum, 2006). These results are in line with results obtained with head impulse testing following neurectomies for therapeutic reasons, for example due to incapacitating Ménière's disease (Halmagyi et al., 1990). Under these circumstances, if there is a parallel time course for deficits in VOR function and those of balance control for these patients, it would be expected that CPAT patients with a neurectomy and those with a neurectomy due to an incapacitating Ménière's disease would have a permanent balance control deficit.

\section{EFFECT OF UNILATERAL PERIPHERAL VESTIBULAR DEFICIT ON THE CONTROL OF STANCE AND GAIT} METHODS OF MEASURING BALANCE CONTROL.

Body mounted sensors can be used to quantify the displacement of the whole body CoM, or its individual segments, during postural sway. Mounting the sensors near the body's CoM at lumbar segments L1-3 helps to provide a clinically oriented picture of the effect of vestibular loss on body stability during stance and gait. In our work we have measured combined pelvis and lower trunk sway at L1-3 with body-worn angular velocity transducers (Gill et al., 2001; Allum and Carpenter, 2005). These transducers have allowed us to track improvements or lack thereof in balance control following onset of a UPVD and compare the rates of balance improvement over time between stance and gait tasks (Allum and Adkin, 2003; Beule and Allum, 2006). The inclusion of both stance and gait tasks in our test battery follows recommendations that this range of tasks should be used to quantify, loss of balance and changes in postural stability when evaluating patients with vestibular deficits (Borello-France et al., 1994).

\section{ACUTE VESTIBULAR NEURITIS}

As documented in Figures 2-6, the balance instability suffered by AVN patients at onset of their deficit is considerable for both stance tasks and gait tasks (Allum and Adkin, 2003). Stance tasks

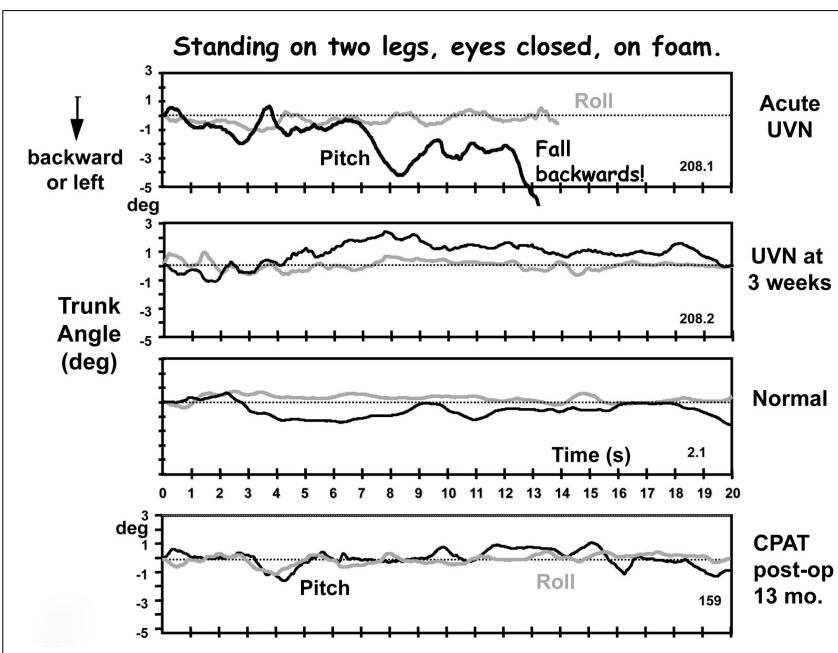

FIGURE 2 | Original traces of pitch and roll movements of the lower back (L1-3) recorded from a patient with an acute peripheral unilateral vestibular neuritis (UVN) while standing eyes closed on a foam surface. The upper traces were recorded in the acute phase (within 5 days of loss onset), the middle traces 3 weeks later. These traces can be compared with those labeled "normal" of a healthy subject of the same age and gender and with those of a CPAT patient 13 months post-operatively. Note the near fall backward after $8 \mathrm{~s}$ until a final loss of balance control at $13 \mathrm{~s}$ in the upper traces. The recording duration of the other traces lasted the full $20 \mathrm{~s}$ of the trial. Data from Allum and Adkin (2003), Beule and Allum (2006). 
with eyes closed lead to considerable instability especially on a foam support surface. A foam support surface reduces the efficacy of ankle proprioceptive inputs and reveals the ability of the vestibular inputs to control body sway because, with eyes closed, visual inputs are not available (Horlings et al., 2009).

We have tested the balance control of patients who are suffering from AVN at three time points: at onset of the deficit and then 3 weeks and 3 months later (Allum and Adkin, 2003). The $3-$ weeks interval was selected based on reports that at this time point AVN patients recover normal control of stance (Fetter et al., 1991; Strupp et al., 1998), neurochemical changes associated with compensation are complete (Li et al., 1997; Vibert et al., 1999a), and spontaneous nystagmus has subsided (Ryu, 1993). The third test point at 3 months coincides with the time point described above when VOR responses to low acceleration (below $100 \% \mathrm{~s}^{2}$ ) whole body rotations in the majority of patients have achieved normal symmetry and gains (Allum et al., 1988a; Allum and Ledin, 1999).

Acute vestibular neuritis patients reduce their excessive body sway rapidly, over the first 3 weeks after the acute onset of symptoms, for the vestibular dependent two-legged stance task, standing eyes closed on foam (see Figures 2-4). Slightly less rapid improvement is noted for one-legged stance tasks (Allum and Adkin, 2003). Sway amplitudes, but not task durations, of simple gait tasks such as walking while turning the head, or walking eyes closed reach age-matched values of healthy controls (normal values) some 49 weeks after AVN onset. Roll sway, and to a lesser extent pitch sway, for more complex gait tasks, such as walking tandem steps on foam, or walking up and down stairs (see Figures 5 and 6) is not within normal limits at 3 months (Allum and Adkin, 2003).

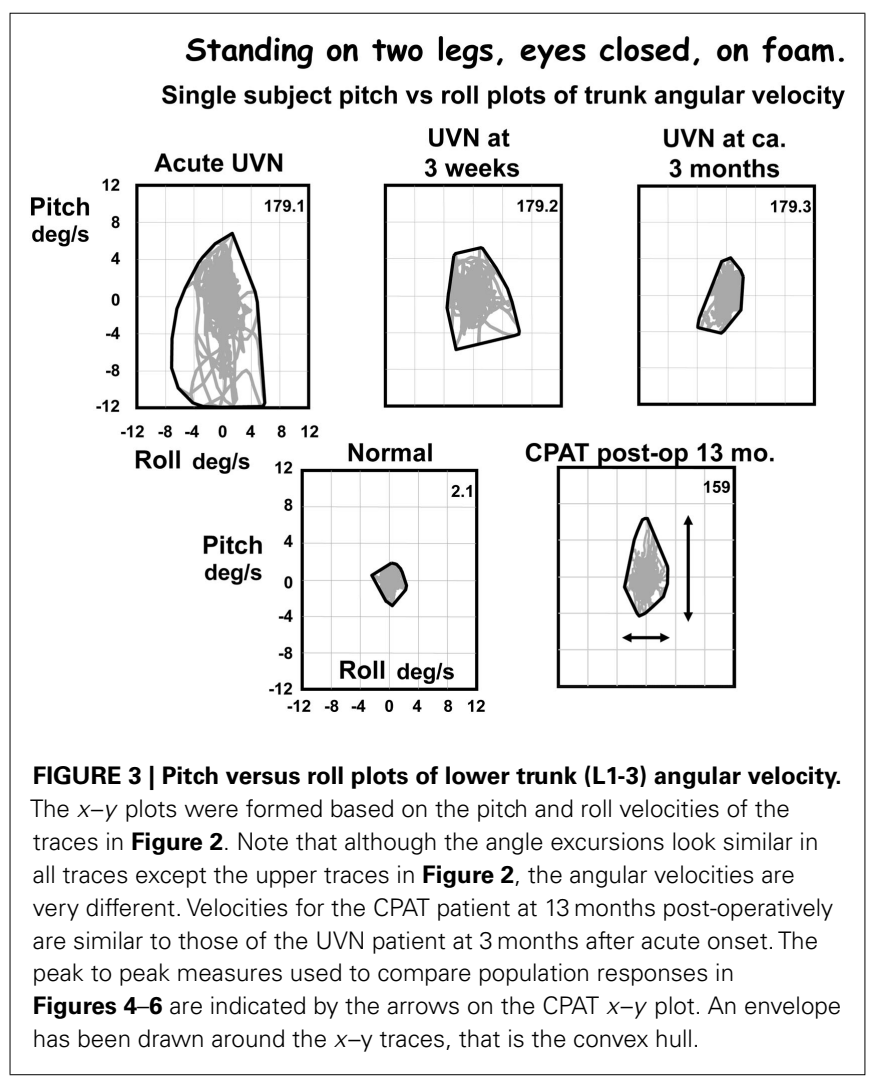

Longer follow-up times would be required to determine when and if AVN patients reach normal values for these tasks.

A number of conclusions can be drawn from results shown in Figures 4-6. Firstly, the reduction of vestibular inputs from one ear is compensated more rapidly for stance compared to gait tasks. This signifies that using stance tasks alone to determine recovery from vestibular loss will provide a misleading underestimate of the patient's recovery. Secondly, it appears that for simple gait tasks, patients aid their stability by performing the task more slowly, thereby reducing their sway velocity. A similar mechanism of compensation has already been noted when normal walking tasks of the elderly were compared to those of the young (Goutier et al., 2010). Thirdly, for those tasks that inherently involved control of roll oscillations coupled with gaze control in planning future gait steps, such as walking tandem steps or up and down stairs, UVN subjects appear unable to control trunk roll oscillations within normal limits at 3 months (we specifically request subjects to look at their feet while walking tandem steps). The difference for these complex gait tasks with a dependence on control of roll compared to the mainly pitch control of simple gait tasks suggests that recovery of trunk roll control is slower compared to that of trunk pitch. This latter finding supports evidence that trunk roll and trunk pitch motion are controlled differently by the CNS (Carpenter et al., 2001; Grüeneberg et al., 2005) due to differing trunk biomechanics present in these planes especially with aging (Allum et al., 2002), and differing use of sensory inputs control balance in these planes (Allum et al., 2008).

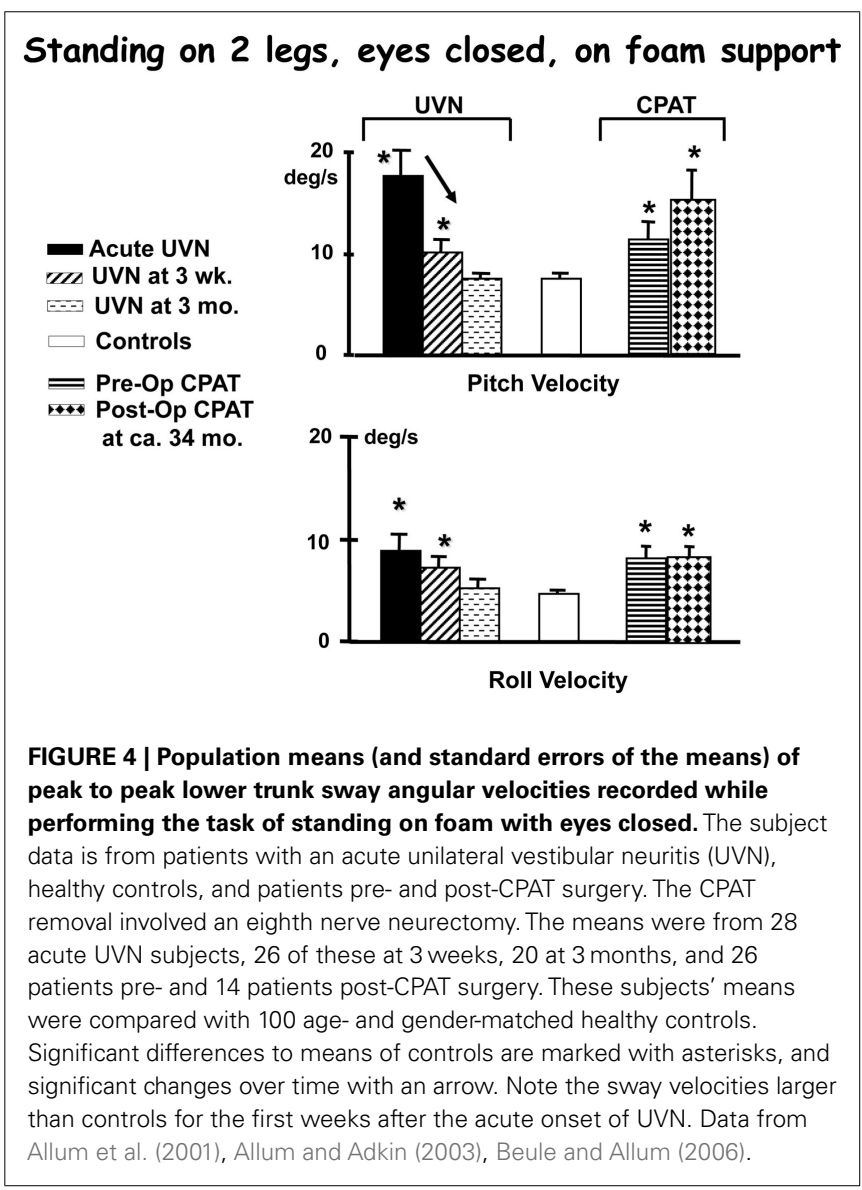




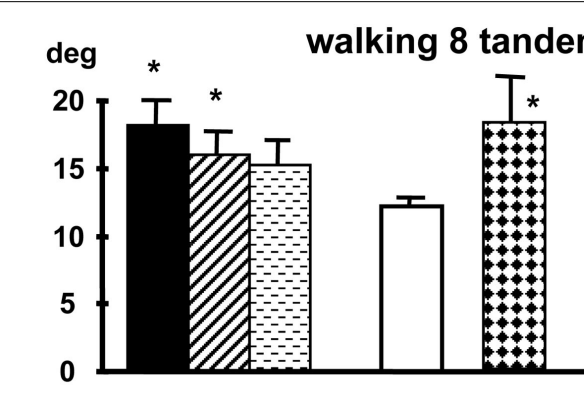

Roll Angle

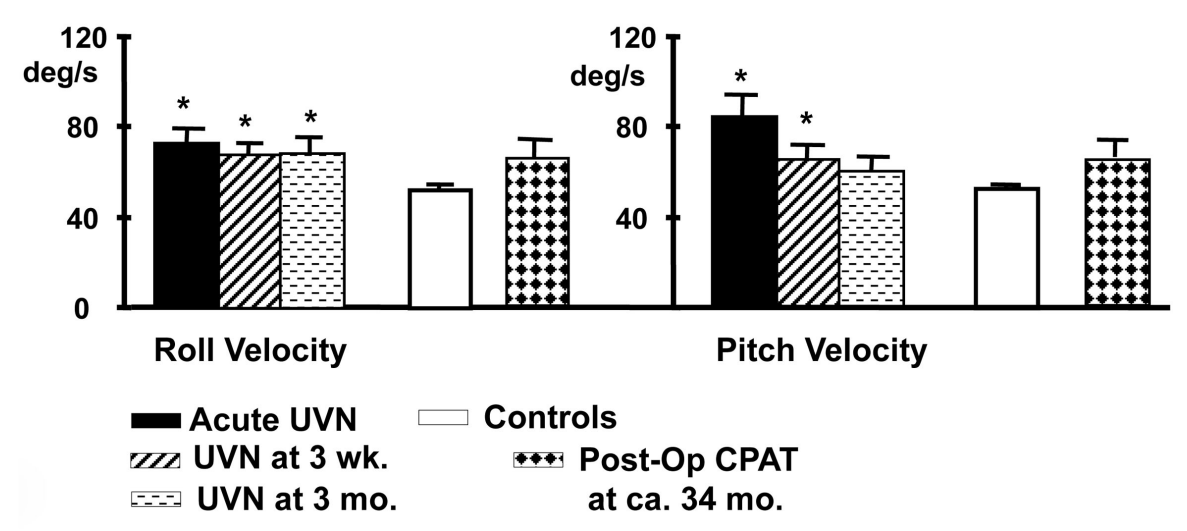

FIGURE 5 | Population means (and standard errors of the means) of peak to peak lower trunk sway angles and angular velocities of subjects with an acute UVN, healthy controls and post-operative patients after CPAT surgery with vestibular neurectomy while performing the task of walking eight tandem steps on a foam support surface. For details of the figure refer to the legend of Figure 4. Note that the angular sway of the CPAT patient is approximately equal to that of the acute UVN patients 3 months after onset. Data from Allum and Adkin (2003), Beule and Allum (2006).
The question arises whether the differing rates of recovery for stance and gait tasks parallel the rates of recovery observed with VOR function. Vestibulo-spinal (VS) and VOR neural pathways are no longer common beyond the vestibular nuclei, even if there may be functional relationships between the two. Thus, deficiencies in VS pathways during gaze fixation would need to be compensated for by enhanced VOR control and vice versa, suggesting that two simultaneous, but independent, compensation processes may well occur. For example, because both the level of spontaneous nystagmus (Ryu, 1993; Curthoys and Halmagyi, 1995) and the stance instability on two legs (Figures 3 and 4) improves dramatically after 3 weeks it is tempting to believe that these two recovery processes are linked. The head sway velocities recorded for stance tasks even under difficult conditions (foam support surface and eyes closed) generally have an amplitude less than $10 \%$ (Honegger et al., 2012), that is of the order of the level of spontaneous nystagmus slow phase velocity during the acute stage of the AVN (Allum and Ledin, 1999). This level of spontaneous nystagmus presumably represents the bilateral static imbalance in afferent vestibular fibers caused by the AVN. Such an imbalance would make the detection of the low velocity head sway deviations involved with two-legged stance more difficult and lead to increased trunk sway.

Once the static imbalance due to UVN has been compensated for, a dynamic imbalance will still be prevalent in the VOR causing saturated responses for head movements toward the deficit side in all three planes (Allum et al., 1988a; Halmagyi et al., 1990; Aw et al., 1996, 1999; Allum and Ledin, 1999). Linking these changes to the changes in gait stability observed in UVN patients is difficult for a number of reasons. Even though, as shown in Figure 1, the velocities observed for head sway during gait tests are roughly equal to the velocities that have been used to test the VOR responses with either whole body or head impulse tests, the rates of compensation of VOR reflexes appear to be different in different planes with vertical canal VOR recovery being faster (Allum et al., 1988a). Based on this literature, the more rapid improvement for gait tasks with horizontal head rotation compared to those with vertical head pitching (Allum and Adkin, 2003) is different to that expected based on the differing rates of improvement for the VOR in these planes (Allum et al., 1988a). If anything the discrepancy between these findings indicates that compensation rates may be different for the VOR and the VS system.

At 3 months after onset of a UVN, the balance control results for gait illustrated in Figures $\mathbf{5}$ and $\mathbf{6}$ indicate a lack of complete compensation. Thus the fundamental difference in recovery processes for a UVN is the difference rates of recovery for stance and complex gait tasks. Therefore, tests after 3 months are required if one wishes to know if UVL patients eventually acquire normal balance control for complex gait tasks. One can not assume that balance control is normal just because VOR gains for left and right head rotations have regained symmetry at this time point (Allum 


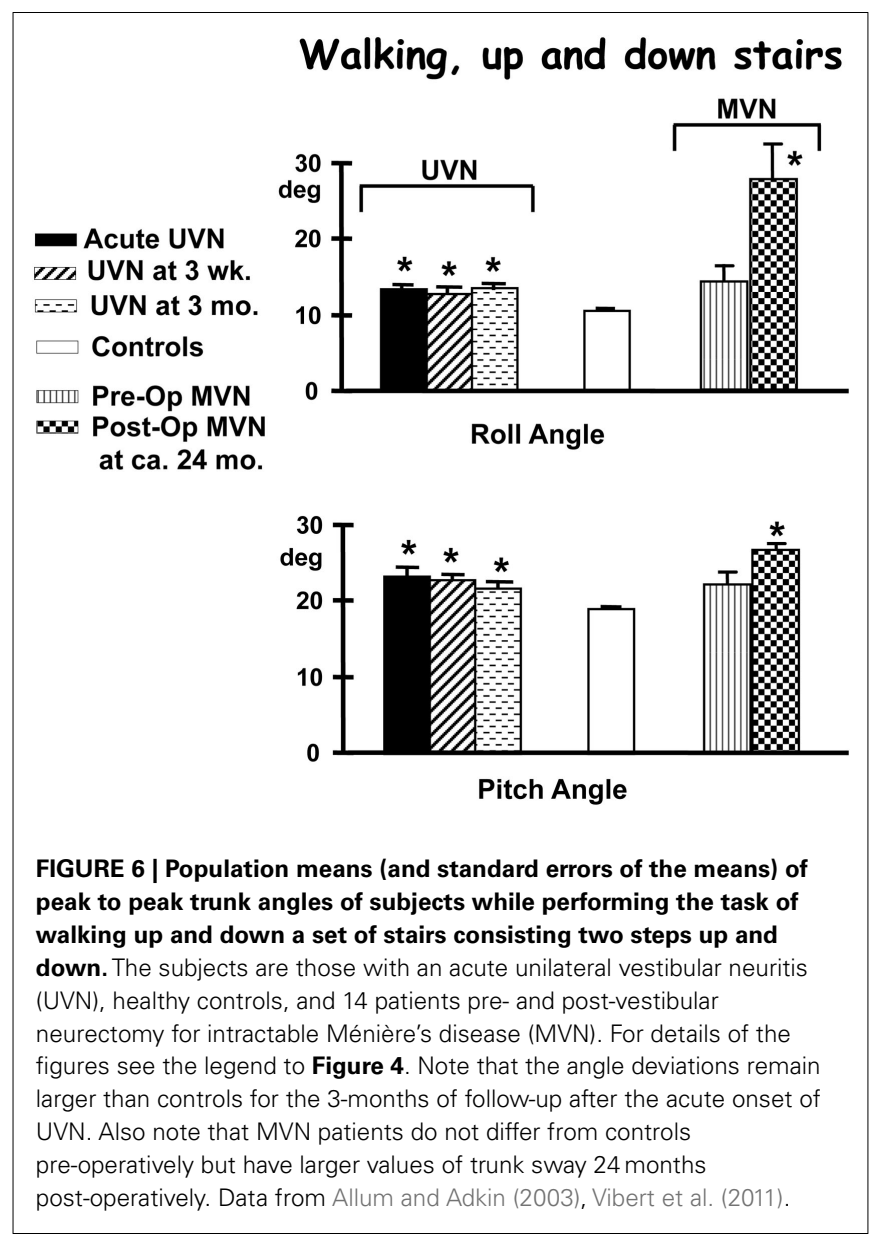

and Ledin, 1999; Palla and Straumann, 2004). Despite reservations mentioned above concerning asymmetry measures for HIT (Weber et al., 2008), it may well be that remaining asymmetries observed with UVN subjects at 3 months (Palla and Straumann, 2004) are the reason that complex gait tests with large head movements would more likely drive the remaining vestibular afferents into saturation and fail to provide adequate VS control due to a lack of contralateral disinhibition.

Another possibility to control the imbalance in VS signals would be to upregulate proprioceptive inputs to balance control. Although evidence has been presented that such upregulation occurs for well compensated neurectomy patients (Peterka et al., 2011) there is no evidence to date that such upregulation occurs for UVN patients. Nonetheless, based on recent neurophysiological studies on monkeys (Sadeghi et al., 2011), it can be assumed

\section{REFERENCES}

Allum, J. H. J., and Adkin, A. L. (2003). Improvements in trunk sway observed for stance and gait tasks during recovery from an acute unilateral peripheral vestibular deficit. Audiol. Neurootol. 8, 286-302.

Allum, J. H. J., and Carpenter, M. G. (2005). A speedy solution for balance and gait analysis: angular velocity measured at the centre of mass. Curr. Opin. Neurol. 18, $15-21$.

Allum, J. H. J., Carpenter, M. G., Honegger, F., Adkin, A. L., and Bloem, B. R. (2002). Age dependent variations in the deviational sensitivity of balance corrections and compensatory arm movements in man. J. Physiol. (Lond.) 542, 643-663.

that such upregulation occurs with UVN patients, just as has been observed in bilateral loss subjects (Schweigart et al., 1993).

Summarizing, recovery rates for VS control of balance following peripheral loss due to neuritis (UVN) appear to be different for the pitch and roll planes, and different for gait and stance tests.

\section{LACK OF RECOVERY OF BALANCE FUNCTION AFTER VESTIBULAR NEURECTOMY}

As may be suspected from the lack of VOR recovery following neurectomy (Halmagyi et al., 1990; Aw et al., 1996), a similar situation occurs with the control of balance via vestibulo-spinal reflexes (VSR). The main difference we will present here concerns the effect of the pre-existing vestibular deficit prior to the neurectomy on balance control.

For example, patients with a chronic UPVD due to a slow growing CPAT may never experience acute balance problems but will nevertheless be unstable when standing (see Figure 4, preoperative values). In contrast, those that have intractable Ménière's disease tend to have normal stance and gait prior to neurectomy (see Figure 6). Post-operatively in both cases, however, the balance deficit is long lasting - far longer lasting than the typical 3 months of neuritis patients. Figures $\mathbf{4} \mathbf{- 6}$ show that for gait tests, the balance deficit is worse than that of neuritis patients. Solely for stance tests does it appear that balance is never as unstable as in the acute stage of neuritis. Interestingly, as Figures 1-3 show, the peak to peak sway angle excursions during stance of neurectomy may not be radically different from those of healthy controls. However, as shown in Figure 2, the control of sway velocity is much worse.

In conclusion, recovery of balance control after a UPVD is highly dependent on the remaining peripheral vestibular function. If some peripheral function remains or even improves post deficit onset then, with the aid of central compensation, a restoration of balance control for stance and simple gait tests can be expected. Without some remaining peripheral function on the lesion side, balance control is not restored to normal. How much of the recovery, when some peripheral function remains, is dependent on restored peripheral function versus central compensation is an issue to be explored in future investigations. However, to explore this issue, velocity profiles of VOR tests used to define the peripheral deficit will need to match head velocity profiles during natural movements of stance and gait.

\section{ACKNOWLEDGMENTS}

The author's research cited in this paper was supported by National Swiss Research Fund grant number 32/11795 to J. H. J. Allum. The author gratefully thanks Ms. Barbara Wenger for her secretarial assistance.

Allum, J. H. J., Held-Ziolkowska, M., Adkin, A. L., Carpenter, M. G., Honegger, F., and Pierchala, K. (2001). Trunk sway measures of postural stability during clinical balance tests: effects of a unilateral vestibular deficit. Gait Posture 14, 227-237.

Allum, J. H. J., and Ledin, T. (1999). Recovery of vestibulo-ocular function in subjects with acute peripheral vestibular loss. J. Vestib. Res. 9, 135-144.

Allum, J. H. J., Oude Nijhuis, L. B., and Carpenter, M. G. (2008). Differences in coding provided by proprioceptive and vestibular sensory signals may contribute to alteral instability in vestibular loss subjects. Exp. Brain Res. 184, 391-410. 
Allum, J. H. J., Yamane, M., and Pfaltz, C. R. (1988a). Long-term modifications of vertical and horizontal vestibulo-ocular reflex dynamics in man. I. After acute unilateral peripheral vestibular paralysis. Acta Otolaryngol. 105, 328-337.

Allum, J. H. J., Yamane, M., Pfaltz, C. R. (1988b). "Vestibular-ocular reflex compensation in the vertical and horizontal planes following unilateral peripheral deficit in man," in Post Lesion Neural Plasticity, ed. H. Flohr (Berlin: Springer-Verlag), 293-304.

Aw, S. T., Halmagyi, G. M., Black, R. A., Curthoys, I. S., Yavor, R. A., and Todd, M. J. (1999). Head impulses reveal loss of individual semicircular canal function. J. Vestib. Res. 9, 173-180.

Aw, S. T., Halmagyi, G. M., Haslwanter, T., Curthoys, I. S., Yavor, R. A., and Todd, M. J. (1996). Three dimensional vector analysis of the human vestibulo ocular reflex in response to high-acceleration head rotations II Responses in subjects with unilateral vestibular loss and selective semicircular canal occlusion. J. Neurophysiol. 76, 4021-4090.

Beule, A. G., and Allum, J. H. J. (2006). Otolith function assessed with the subjective postural horizontal and standardised stance and gait tests. Audiol. Neurootol. 11, 172-182.

Borello-France, D. F., Whitney, S. L., Herdman, S. J., et al. (1994). "Assessment of vestibular hypofunction," in Vestibular Rehabilitation, ed. S. J. Hardman (Philadelphia, FA: Davis Co), 247-286.

Carpenter, M. G., Allum, J. H. J., and Honegger, F. (2001). Vestibular influences on human postural control in combinations of pitch and roll planes reveal differences in spatiotemporal processing. Exp. Brain Res. 140, 95-111.

Cremer, P. D., Halmagyi, G. M., Aw, S. T., Curthoys, I. S., McGarvie, L. A., Todd, M. J., Black, R. A., and Hannigan, I. P. (1998). Semicircular canal plane head impulses detect absent function of individual semicircular canals. Brain 121, 699-716.

Curthoys, I. S. (2000). Vestibular compensation and substitution. Curr. Opin. Neurol. 13, 27-30.
Curthoys, I. S., and Halmagyi, G. M. (1995). Vestibular compensation: a review of the oculomotor, neural, and clinical consequences of unilateral vestibular loss. J. Vestib. Res. 5, 67-107.

Fetter, M., Diener, H. C., and Dichgans, J. (1991). Recovery of postural control after an acute unilateral vestibular lesion in humans. J. Vestib. Res. 1, 373-383.

Gill, J., Allum, J. H. J., Carpenter, M. G., Held-Ziolkowska, M., Honegger, F., and Pierchala, K. (2001). Trunk sway measures of postural stability during clinical balance tests: effects of age. J. Gerontol. 56A, M438-M447.

Goutier, K. M. T., Jansen, S. L., Horlings, G. C., Küng, U. M., and Allum, J. H. J. (2010). The influence of walking speed and gender on trunk sway for the healthy young and older adults. Age Ageing 39, 647-650.

Grüeneberg, C., Duysens, J., Honegger, F., and Allum, J. H. J. (2005). Spatio-temporal separation of roll and pitch balance-correcting commands in humans. J. Neurophysiol. 94, 3143-3158.

Halmagyi, G. M., and Curthoys, I. S. (1988). A clinical sign of canal paresis. Arch. Neurol. 45, 737-739.

Halmagyi, G. M., Curthoys, I. S., Cremer, P. D., Henderson, C. J., Todd, M. J., Staples, M. J., and O'Cruz, D. M. (1990). The human horizontal vestibulo-ocular reflex in response to high acceleration stimuli before and after unilateral vestibular neurectomy. Exp. Brain Res. 81, 479-490.

Halmagyi, G. M., Weber, K. P., and Curthoys, I. S. (2010). Vestibular function after acute vestibular neuritis. Restor. Neurol. Neurosci. 28, 37-46.

Herzog, N., Allum, J. H. J., and Probst, R. (1997). Verlauf der kalorischen Erregbarkeit nach akuter peripherer vestibulärer Funktionsstörung. HNO 45, 123-127.

Honegger, F., Van Spijker, G. J., and Allum, J. H. J. (2012). Coordination of the head with respect to the trunk and pelvis in the roll and pitch planes during quiet stance. Neuroscience. (in press).

Horlings, C. G. C., Kueng, U. M., Bloem, B. R., Honegger, F., Van Engelen, B. G. M., and Allum, J. H. J. (2009).
Vestibular and proprioceptive influences on trunk movement strategies during quiet standing. Neuroscience 161, 904-914.

Li, H., Godfrey, D. A., and Rubin, A. M. (1997). Quantitative autoradiography of 5-[ $\left[{ }^{3}\right] 6$-cyano-7-nitroquinoxaline-2,3-dione and (+)-3$\left[{ }^{3} \mathrm{H}\right]$ dizocilpine maleate binding in rat vestibular nuclear complex after unilateral deafferentation, with comparison to cochlear nucleus. Neuroscience 77, 473-484.

MacDougall, H. G., Weber, K. P., McGarvie, L. A., Halmagyi, G. M. and Curthoys, I. S. (2009). The video head impulse test: diagnostic accuracy in peripheral vestibulopathy. Neurology 73, 1134-1141.

Manzari, L., Burgess, A. M., MacDougall, H. G., and Curthoys, I. S. (2011). Objective verification of full recovery of dynamic vestibular function after superior vestibular neuritis. Laryngoscope 121, 2496-2500.

Palla, A., and Straumann, D. (2004). Recovery of the high-acceleration vestibulo-ocular reflex after vestibular neuritis. J. Assoc. Res. Otolaryngol. 5, 427-435.

Peterka, R. J., Statler, K. D., Wrisley, D. M., and Horak, F. B. (2011). Postural compensation for unilateral vestibular loss. Front. Neurol. 2:57. doi:10.3389/fneur.2011.00057

Ried, S., Maioli, C., and Precht, W. (1984). Vestibular nuclear neuron activity in chronically hemilabyrinthectomized cats. Acta Otolaryngol. 98, 1-13.

Ryu, J. H. (1993). Vestibular neuritis: an overview using a classical case. Acta Otolaryngol. Suppl. 503 , 25-30.

Sadeghi, S. G., Minor, L. B., and Culler, K. E. (2011). Multimodal integration after unilateral labyrinthine lesion: single vestibular nuclei neuron responses and implications for postural compensation. J. Neurophysiol. 105, 661-673.

Schweigart, G., Heimbrand, S., Mergner, T., and Becker, W. (1993). Perception of horizontal head and trunk rotation: modification of neck input following loss of vestibular function. Exp. Brain Res. 95, 533-546.

Strupp, M., Arbusow, V., Maag, K. P., Gall, C., and Brandt, T. (1998). Vestibular exercises improve central vestibulospinal compensation after vestibular neuritis. Neurology 51, 838-844.

Vibert, D., Stieger, C., Wiedmer, S, Allum, J. H. J., Häusler, R., and Caversaccio, M. (2011). Measurements of trunk sway for stance and gait tasks 2 years after vestibular neurectomy. Abstract for the 38th Meeting of the Neurootological Equilibriometric Society.

Vibert, N., Babalian, A., Serafin, M., Gasc, J.-P., Muhlethaler, M., and Vidal, P.-P. (1999a). Plastic changes underlying vestibular compensation in the guinea-pig persist in isolated in vitro whole brain preparations. Neuroscience 93, 413-432.

Vibert, N., Bantikyan, A., Babalian, A., Serafin, M., Muhlethaler, M., and Vidal, P.-P. (1999b). Post-lesional plasticity in the central nervous system of the guinea-pig: a "top-down" adaption process? Neuroscience 94, $1-5$.

Weber, K. P., Aw, S. T., Todd, M. J., McGarvie, L. A., Pratap, S., Curthoys, I. S., and Halmagyi, G. M. (2008). Inter-ocular differences of the horizontal vestibulo-ocular reflex during impulsive testing. Prog. Brain Res. 171, 195-198.

Conflict of Interest Statement: The author declared that he has worked as a consultant for the company producing one of the measurement systems (SwayStar) described in this review. This system was used to measure balance control with body-mounted sensors.

Received: 01 February 2012; accepted: 26 April 2012; published online: 16 May 2012.

Citation: Allum JHJ (2012) Recovery of vestibular ocular reflex function and balance control after a unilateral peripheral vestibular deficit. Front. Neur. 3:83. doi: 10.3389/fneur.2012.00083

This article was submitted to Frontiers in Neuro-otology, a specialty of Frontiers in Neurology.

Copyright (c) 2012 Allum. This is an open-access article distributed under the terms of the Creative Commons Attribution Non Commercial License, which permits non-commercial use, distribution, and reproduction in other forums, provided the original authors and source are credited. 